\title{
La Paloma: uma história de amor, carros em fanzine
}

DOI: https://doi.org/10.35168/2176-896X.UTP.Tuiuti.2020.Vol7.N62.pp18-45

Hector Pereira de Azevedo Graduando do curso Superior de Tecnologia em Fotografia (2020) na Universidade Tuiuti do Paraná (UTP) - Hektorkister@gmail.com

Daniel Oikawa Lopes

Professor da Universidade Tuiuti do Paraná, Brasil. Mestrado em Estudos de Linguagens pela Universidade Tecnológica Federal do Paraná. E-mail: daniel.lopes@utp.br 


\section{La Paloma: uma história de amor, carros em fanzine}

\section{Resumo}

O presente artigo apresenta um ensaio fotográfico construído a partir de apropriação de imagens e registros fotográficos de uma viagem para o Uruguai e apresentado a partir do formato de um fanzine. O processo de criação do trabalho foi inspirado nos registros fotográficos da família da Luana, minha namorada e nas histórias sobre seus avós nas terras uruguaias. Além dessas histórias, tenho como inspiração pessoal minha ligação com a cultura automotiva presente no país. A pesquisa teórica partirá do artigo de Rony Maltz, sobre fanzines e fotografia, publicado na Revista Zum, e, no que diz respeito à sua origem e os nichos no qual ele se popularizou, recorro à dissertação de Denise Lourenço sobre o tema e os procedimentos para sua construção. Sobre a fotografia contemporânea, conto com Greice Schneider, ao pensar na sequência das imagens e estrutura do fanz̧ine, além dos estudos de Tate Shaw sobre sequenciamento de fotografias em foto livros.

Palavras-chave: Fotografia. Fan̨ine. Memória. Apropriação de imagens. 


\section{La Paloma: uma história de amor, carros em fanzine}

\section{Apresentação}

Por meio desse artigo apresento um ensaio fotográfico a partir de imagens e registros fotográficos de uma viagem para o Uruguai, que será apresentado na forma de um fanzine. Primeiro relato as histórias que me motivaram a realizar esse sonho e produzir uma homenagem a elas. As histórias têm como base uma vontade de infância de garimpar veículos antigos. Essa paixão pelos carros me aproximou de muitas pessoas, e em meio a isso, graças a um sonho de um colega, comecei a ver com outros olhos as terras uruguaias. Tempos depois desse primeiro contato, veio a motivação que faltava para conhecer esse país, a história da família de Luana, minha namorada.

A história de amor de Mabel e Gabino me convenceu que deveria conhecer o palco no qual tudo aconteceu, mas, ao invés de tentar contar esses acontecimentos, optei por registrar a minha experiência criando uma conexão por meio das sobreposições de imagem dos álbuns da família que me apropriei.

Porém, para desenvolver esse trabalho é necessário apresentar o que é um fanzine. Como não existe ao certo indícios de sua origem em específico, apresento os pontos mais importantes sobre os meios de produção no qual ele passou a ser mais difundido e de como ele se aplicou no meio fotográfico, ponto esse que uso para estruturar meu projeto.

\section{Regresso a La Paloma': uma história de amor e longas viagens}

Vinte dias depois e mais quatro mil quilômetros rodados na conta, ainda custo a acreditar que realizei o sonho de fazer uma grande viagem de carro. Estou muito cansado para pensar em tudo

10 título remete a uma música da cantora Argentina, Mercedes Sosa. Cantora essa que era uma das favoritas de dona Mabel, por isso mantive a escrita em Espanhol. 


\section{La Paloma: uma história de amor, carros em fanzine}

o que aconteceu, parece que estou há dias nessa estrada, porém, apenas algumas horas se passaram desde que cruzei a fronteira do Uruguai. Os assuntos foram acabando, as músicas se tornaram enjoativas, apenas o barulho do motor ecoa pelo ambiente e me mantém acordado.

Quando paro pra pensar, lembro que a primeira vez que cogitei viajar para o Uruguai foi motivado pelo sonho de um amigo, que tinha como objetivo ir para lá buscar carros antigos e restaurar no Brasil. Apesar da ideia soar como algo digno de um filme, não passava do fruto de uma visão adolescente. Por arrogância e ceticismo, o desencorajei. Hoje não me sinto bem por ter feito isso, não estava no direito de destruir esse sonho, que, desde aquele dia me acompanhou e despertou meu interesse.

Anos depois dessa história eu conheci a minha namorada, Luana, e, por ironia do destino, o Uruguai voltava a ser um tema presente. Quando começamos a nos conhecer, ela me contou a história de sua família e toda a trama de amor e ódio que renderia um ótimo roteiro de novela mexicana. Sua avó, Dona Mabel, era uma mulher independente, em uma época que isso era ainda visto com maus olhos. Depois de três relacionamentos abusivos e de não ser acolhida por sua família, ela decidiu que era hora de buscar melhores condições não só para ela como para os filhos. Trabalhando e viajando por vários lugares Uruguai a fora, chegou a morar em uma barraca com os filhos. Sua vida iria mudar no dia que ela reencontrou o grande amor de sua vida, o fisioterapeuta de sua avó, a quem conhecia desde a infância. Desde sempre, Gabino prometeu a Mabel que um dia se casaria com ela, tendo se declarado até durante as consultas da sua avó, mas sempre foi ignorado.

Mesmo com um casamento de prestígio com Olga, a então miss Uruguai, Gabino seguiu com uma vida movimentada, em vários momentos escapando da sua cidade, Rocha, para a badalada 


\section{La Paloma: uma história de amor, carros em fanzine}

Punta del Este, para tirar férias da vida de casado. Em uma dessas idas e vindas foi que seu caminho voltou a se encontrar com o de Mabel, que vivia e trabalhava em Punta. Essa paixão proibida rendeu um fruto, porém, ao se mudarem para La Paloma, cidade que fica aproximadamente a 30 quilômetros de Rocha, esse romance foi descoberto pela matriarca da família de Gabino, que não ficou nenhum pouco contente com a repercussão que isso causaria no status de sua família. Tamanho foi o descontentamento que ela planejou a morte de Mabel e de sua filha, ainda na maternidade.

Por mais que isso soe extremo, aquela era uma época e local completamente diferente, o país passava por um período de ditadura, os conflitos eram intensos até mesmo dentro da família. O lado da matriarca tinha um prestígio político militar e não poderia ser manchado com tal ato. Graças à influência de Gabino, ele soube dos planos de sua mãe por uma de suas colegas de trabalho do hospital. Do outro lado da história, sua esposa Olga vivia com a vergonha de ter sido trocada, cuidando de seus dois filhos, tendo tentado inúmeras vezes se afogar nas águas da praia de La Paloma. Sabendo do histórico de sua família, em que um dos tios de Mabel já havia sido capturado e torturado por seu cunhado, Gabino e Mabel não viram outra alternativa senão a fuga do Uruguai. E assim nasceu Natalia, minha sogra, que apenas aos 15 anos conseguiu o perdão de sua avó.

Ao ouvir essa história, acabei me interessando mais ainda pelo Uruguai, queria conhecer os lugares que serviram de palco para essa trama familiar, que conquistou até mesmo alguém que sequer gostava de histórias de amor. Todas essas memórias me emocionam, mesmo que eu nem tenha contato com as pessoas mencionadas, muitas eu sequer conheci, como os avós de Luana, e torna uma simples viagem em uma terra desconhecida algo muito mais interessante. E, a partir de cada foto gostaria de prestar uma homenagem a essa história, com isso me veio um estalo de que a 


\section{La Paloma: uma história de amor, carros em fanzine}

melhor forma de conduzir seria através de um zine. Algo que por muitos anos já tinha vontade de produzir, mas não achava um tema que me cativasse. Pensar nessa história e em todos os motivos dessa viagem me fazem querer seguir mais rápido por essa estrada, tornando ela menos cansativa e tediosa, ainda faltam muitos quilômetros até o meu lar, mas agora tenho um tema e uma ideia para trabalhar, e uma pergunta que preciso responder, o que é um fanzine?

\section{Fanzine, uma breve introdução a sua história}

O fanzine ou também conhecido como żine, está muito relacionado aos movimentos Punk e estudantil, além de outros movimentos culturais, sociais e políticos. É visto como uma alternativa barata e acessível para produção e distribuição de informação, e para a difusão de ideias. O seu nome vem da contração da palavra fã com a palavra magażine como mencionado no artigo Zines e fotografia: Uma história de resistência em tempos digitais, de Rony Maltz para a Revista Zum,

\footnotetext{
O nome zine vem do sufixo de maganize (revista, em inglês), que, por sua vez, tem raiz no árabe "armazém" (Al-Makhzan): depósito de todo tipo de mercadorias, lugar que comporta diversidade e variedade. Como os fanzines - revistas feitas por fãs sobre algum artista, grupo ou produto midiático-, os zines costumam ter estética amadora e rede de distribuição informal. Sem temática especifica, em geral não são serializados ou padronizados como os periódicos (REVISTA ZUM, 2018).
}

Seguindo o conceito do "faça você mesmo", sua proposta era dar maior liberdade criativa seguindo um método de montagem menos sofisticado em comparação às revistas comerciais. 


\section{La Paloma: uma história de amor, carros em fanzine}

Utilizando matéria prima e técnicas de reprodução baratas, seu produto final garantia uma forma mais ágil na articulação e execução de um projeto. Seu método se distanciava dos grandes canais de distribuição e se aproximava mais de um público-alvo seleto.

Existe uma dificuldade em elaborar uma pesquisa acadêmica sobre fanżine, já que não existe um ponto de partida específico ou algo que determine onde esse tipo de prática surgiu oficialmente, apenas à ideia simplificada e repetida inúmeras vezes de que o fanzine não passa de uma revista de fã ou revista alternativa (LOURENÇO, 2006, p. 1) Porém, quando há um aprofundamento na pesquisa sobre o tema, é notável sua participação na história de muitos movimentos sociais, culturais e políticos, como um meio de comunicação alternativo e livre de limitações comerciais ou fórmulas de criação.

Isso lhe garantia um status de mídia livre, que não precisaria passar pelo controle do mercado, ou ainda da censura, que era muito comum em regimes militares, como o que aconteceu no Brasil a partir do ano de 1964. Nessa época, os fanzines circulavam distante dos radares da censura que controlava os meios de comunicação tradicionais com objetivo de criminalizar ideias que estavam na contramão dos ideais pregados pelo governo. Com isso os fanzines serviam como uma forma de difundir essas ideias para um público que fosse alinhado aos mesmos ideais e que buscava liberdade de expressão.

Entretanto, na medida em que o trabalho de pesquisa se aprofundou, percebemos que o termo "alternativo" relacionado as revistas da imprensa alternativa ao regime militar do Brasil entre 1964 e 1979 (Kucinski, 1991) como O Pasquim, O sol, Opinião, Ex, Pif-Paf, Bondinho, alcançou status de qualidade, por seu poder de luta contra a impressa formal, 


\section{La Paloma: uma história de amor, carros em fanzine}

conferido pelo trabalho de jornalistas e ilustradores que mantiveram essas produções como Tarso de Castro, Millôr Fernandes, Henfil, Ziraldo, Raimundo Pereira, Sergio Souza, dentre outros. (LOURENÇO, 2006, P1)

A visão de mídia alternativa ganha dois pontos de vista quando pensado nesse contexto, por exemplo; O Pasquim (FIGURA 1) era um jornal alternativo que se diferenciava dos grandes jornais tradicionais por optar por um viés cômico, vide a capa com a cantora Rogéria como Monalisa na edição de 1973. Irreverente e sem as amarras de um produto de redação, mas ainda assim ele tinha todo um cuidado no produto final. Uma equipe de redatores e que mesmo que em menor número, se assimilava muito a uma redação tradicional. Mas ao pensarmos em fanzine, o termo alternativo ganha um caráter pejorativo, por ser tratar de algo feito com menos recursos (FIGURA 2) com matéria prima barata que facilitava sua distribuição, como nos é apresentado no zine punk sul africano Obscenely Loud. Essas características eram negativas no resultado final, sendo basicamente uma mídia descartável.

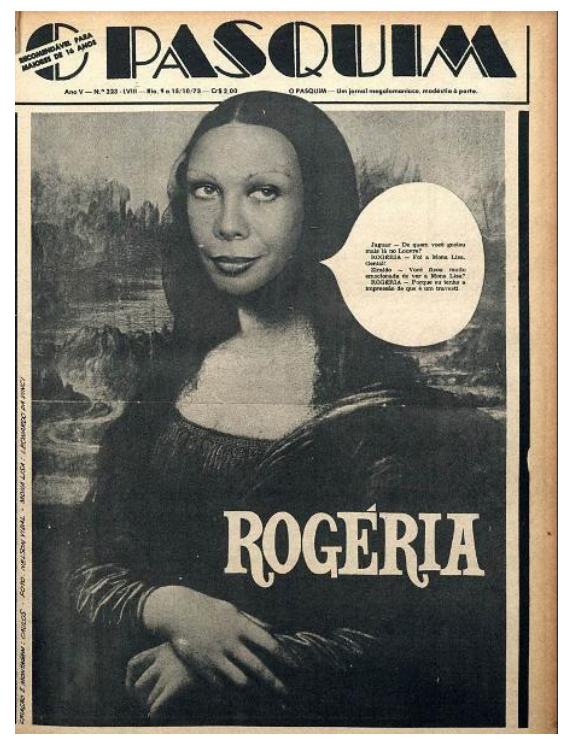

(FIGURA1) Capa do jornal O pasquim, de Jaguar, Tarso de castro e Sergio Cabral, 1973, autopublicado Fonte: Entretenimento Uol 


\section{La Paloma: uma história de amor, carros em fanzine}

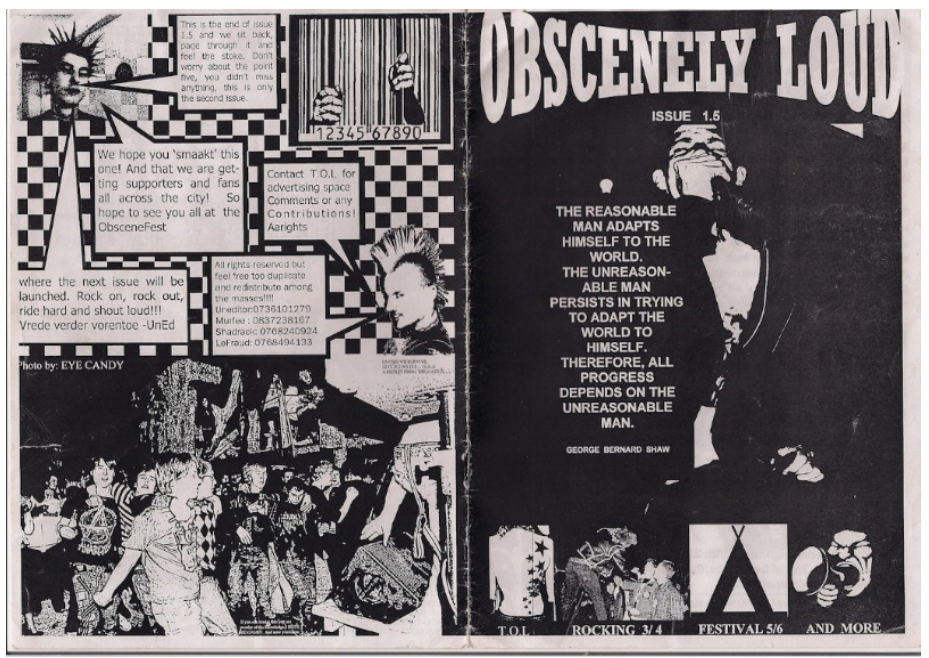

(FIGURA2) Zine punk sul africano Obscenely Loud, de Murray Stassen, 2006, autopublicado

Fonte: Vice Magazine

Devido à praticidade e baixo valor de produção, muitos fotógrafos viram no zine uma alternativa acessível de produção e distribuição do seu trabalho. Ed Ruscha, em 1963, em que o mesmo por conta própria publicou Vinte e seis postos de gasolina (FIGURA 3), com objetivo de que a obra fosse distribuída por um valor acessível. (MALTZ,2018) Outro ponto a favor do fanzine era o maior contato com a sua arte, desde a escolha dos materiais, diagramação e intervenções que seriam feitas no zine. 


\section{La Paloma: uma história de amor, carros em fanzine}

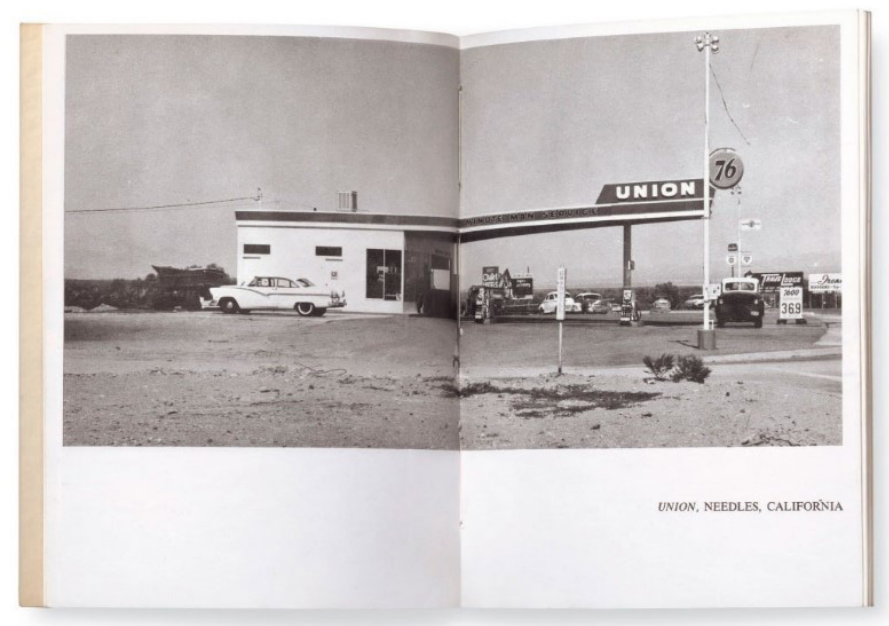

Reprodução do livro Vinte e seis postos de gasolina, de Ed Ruscha, 1963, autopublicado.

Fonte: Revista Zum

Partindo disso, tive a primeira ideia para produzir meu trabalho, construir uma serie fotográfica que fosse viável tanto para produção quanto para distribuição. Não só pensando na questão financeira, mas sim na liberdade criativa, na qual pudesse explorar inúmeras alternativas de edição e montagem desse material, que se adequariam melhor ao fanzine do que ao formato tradicional de um foto livro. 


\section{La Paloma: uma história de amor, carros em fanzine}

\section{Idealizando La Paloma e seu conceito visual}

Como já mencionado anteriormente, muitos fotógrafos usaram da liberdade do zine para criar suas series fotográficas de um modo mais orgânico. Porém quando pensamos em uma visão voltada para o fotojornalismo ou fotodocumentarismo esse aspecto é pouco explorado por conta das regras que costumam ser seguidas nesses gêneros, por conta disso, foi necessário uma busca por um caminho que se adequasse a proposta do zine.

Markus Jokela em 1992 iniciou um projeto chamado Table Rock, no qual sua pesquisa consistia em registrar o cotidiano da pacata comunidade de 255 habitantes ao nordeste de Nebraska. Diferente do discurso tradicional do fotojornalismo, que busca o registro preciso do momento, popularmente conhecido como "Momento decisivo" a abordagem de Jokela era de um anti momento, buscando uma visão mais autoral do registro cotidiano. No fotojornalismo tenta se apagar as marcas do autor e investir em um discurso mais transparente (SCHNEIDER, 2015) aqui a ideia é totalmente oposta, dando um caráter mais íntimo e cru com um aspecto quase que amador, como cita Fred Ritchin em Bending the frame.

As imagens mais cruas, de primeira e de segunda pessoa, encontradas nas mídias sociais referindo-se ao 'eu' (o fotógrafo) e 'nós' (os amigos, família e comunidade) são vistas como, pelo menos, tão autênticas quanto as fotografias mais esteticamente harmoniosas, de terceira pessoa, indiretas, feitas por profissionais jornalísticos. Profissionais devem não somente produzir imagens que se encaixam às necessidades de publicações - que têm seus próprios estilos particulares e visões de mundo - mas também tentar esconder, em sua maior parte, as suas próprias reações pessoais para as situações que experimentam (RITCHIN,2013, p.10) 


\section{La Paloma: uma história de amor, carros em fanzine}

Partindo dessa premissa, entendemos o contexto que diferencia a visão de Jokela dos demais fotógrafos, como podemos ver na seguinte imagem (FIGURA 4). Esse aspecto amador do cotidiano e uma maior proximidade com os que estão sendo fotografados são alguns dos elementos que se destacam de uma fotografia tradicional. Para melhor visualizar essa ideia, a fotografia de Steve McCurry (FIGURA 5), de um ambiente de guerra, é uma imagem com um aspecto íntimo e pessoal, mas carregada de signos do fotojornalismo tradicional, por mais que ela tem uma proximidade do fotógrafo com as pessoas fotografadas, fica bem claro o aspecto mais distante das marcas do autor e do discurso de neutralidade.

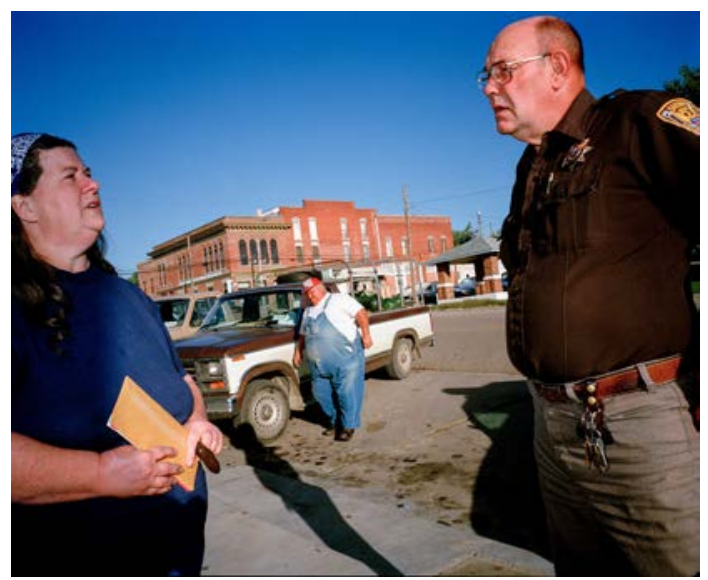

(Fig.4) Mary Lou Waters, Myron Kent e o Xerife Schulze do lado de fora da taberna Table Rock. Markus Jokela, 1992, Wordpress photo

Fonte: Worldpress Photo 


\section{La Paloma: uma história de amor, carros em fanzine}

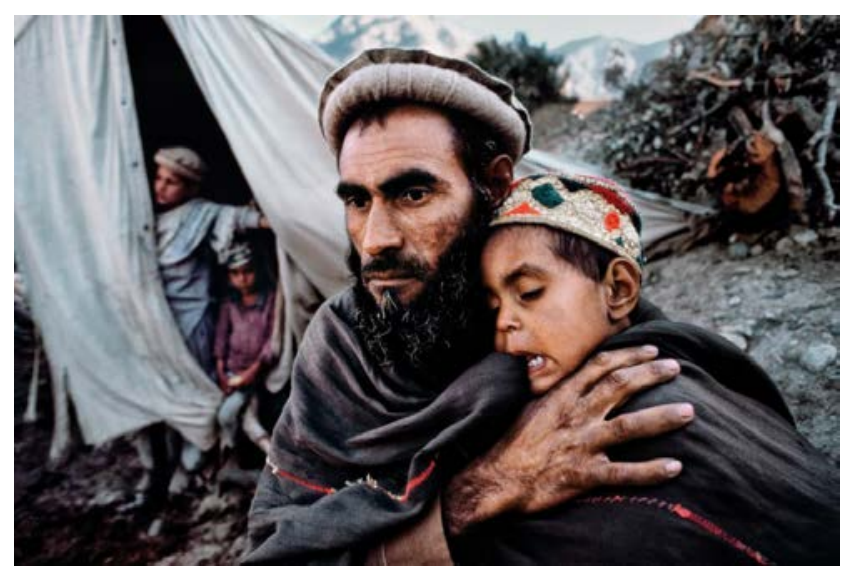

(Fig 5) Familia Afegã, Steve McCurry, 1979-1989

Fonte: Steve McCurry

Por se tratar de fotografia de viagens, existe um discurso de registrar os pontos turísticos, monumentos históricos e paisagens com a menor quantidade de pessoas possíveis, dando aquele aspecto de guia turístico. Se tratando de um trabalho mais pessoal, além de registrar momentos familiares, um dos intuitos era explorar uma visão muito mais orgânica em relação ao Uruguai. Por exemplo, a (FIGURA 6), mostra uma imagem comum a se fazer em uma viagem ao país, um monumento tradicional da cidade, Los Dedos, na praia de Punta Del Este, representado com sombras do entardecer e mar ao fundo. Porém, quando estive no local, me deparei com um ambiente cheio, repleto de turistas em todos os lados do monumento, cena essa que se tornou motivo de frustração 


\section{La Paloma: uma história de amor, carros em fanzine}

para os membros de minha família, que pretendiam tirar uma foto turística tradicional em frente ao monumento. Vi nessa situação uma boa oportunidade para foto (FIGURA 7) e, ao invés de pensar em uma imagem tentando tirar todas aquelas pessoas de cena, me foquei em construir uma boa foto da Luana e de minha sogra Natalia, usando o local como um plano de fundo e valorizando o que realmente me interessava.

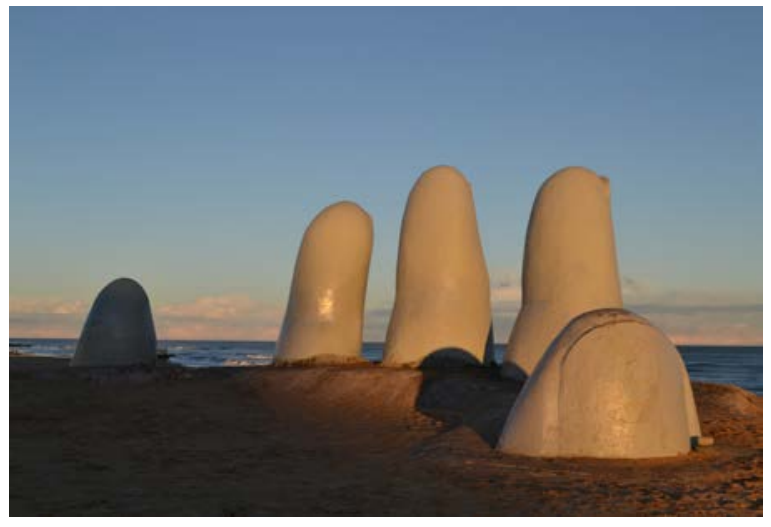

(Fig 6) Los Dedos, monumento de Punta del Este.

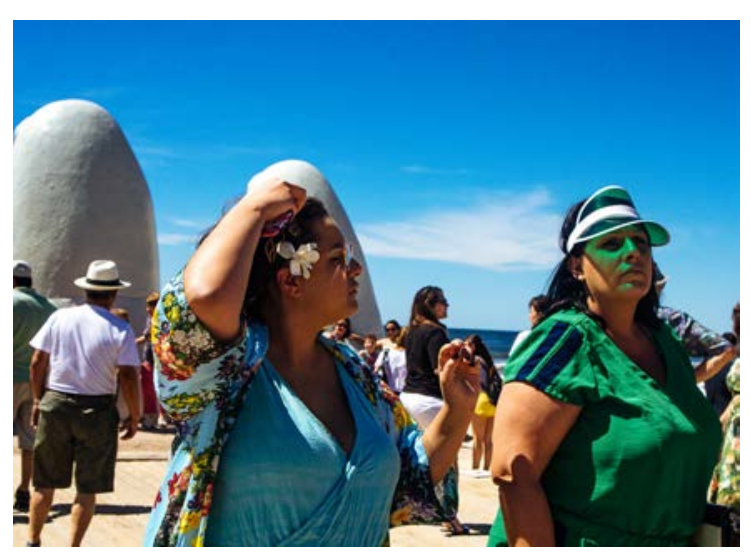

(Fig 7) Luana e Natalia, Hektor Kister, 2019.

Punta del Este Hoteis.

Esse registro do não acontecimento, no qual, por mais que exista uma preocupação estética e até mesmo uma técnica apurada, o produto final visa mais registrar uma cena de interesse pessoal do que um momento marcante e decisivo, é atrelado aos fotógrafos amadores, tendo sido incorporado 


\section{La Paloma: uma história de amor, carros em fanzine}

à fotografia autoral e documental contemporânea. Isso é bastante presente nas imagens de Jokela, já que muito do que ele registrou é a vida cotidiana de uma pequena comunidade, muito do que acontece nesse ambiente são momentos sem muita relevância para quem está fora, por exemplo, essa cena (FIGURA 8) de uma senhora pegando suas correspondências, poderia facilmente ser encontrado em algum álbum de família. Tudo nessa imagem remete a um amadorismo proposital, com intuito de criar um vínculo pessoal com o espectador, assim como quando folheamos um álbum de família que não é a nossa.

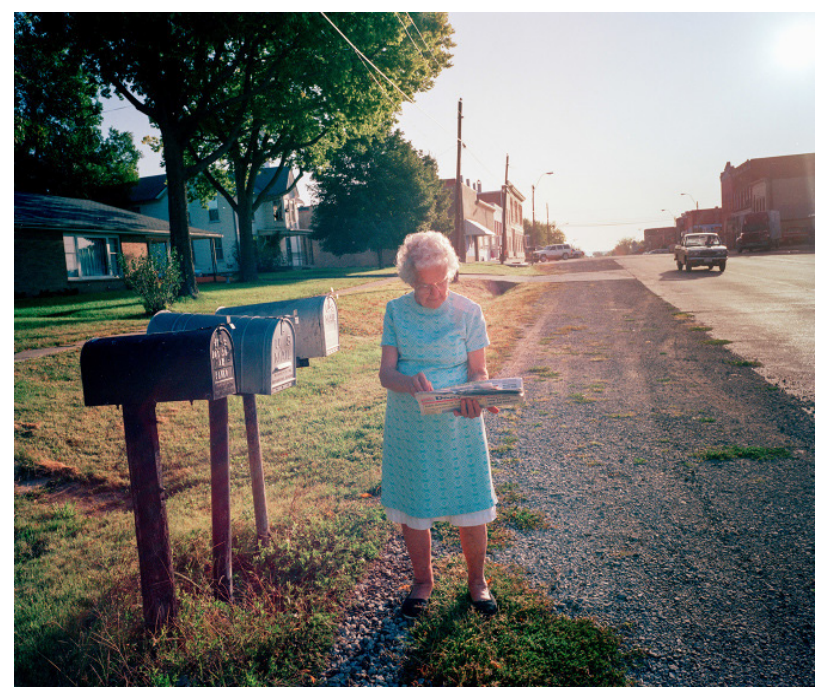

(Fig 8) Libby Kalina coletando as correspondências, Markus Jokela, Worldpress photo.

Fonte: Worldpres Photo 


\section{La Paloma: uma história de amor, carros em fanzine}

Esse discurso fica claro na minha serie, quando nos deparamos com fotos de momentos pessoais, como por exemplo, na (FIGURA 9), na qual estávamos todos reunidos na beira da piscina da casa que alugamos em Colonia del Sacramento. Por se tratar de um momento mais familiar, estava usando uma Canon AS1, uma câmera analógica saboneteira (FIGURA 10). Por ser subaquática, me possibilitou algo ideal ao se pensar em registros de família. Na (FIGURA 11), algumas fotos da Luana e família na piscina. Tudo isso foi pensado propositalmente para passar essa proximidade a quem estivesse visualizando essa imagem.

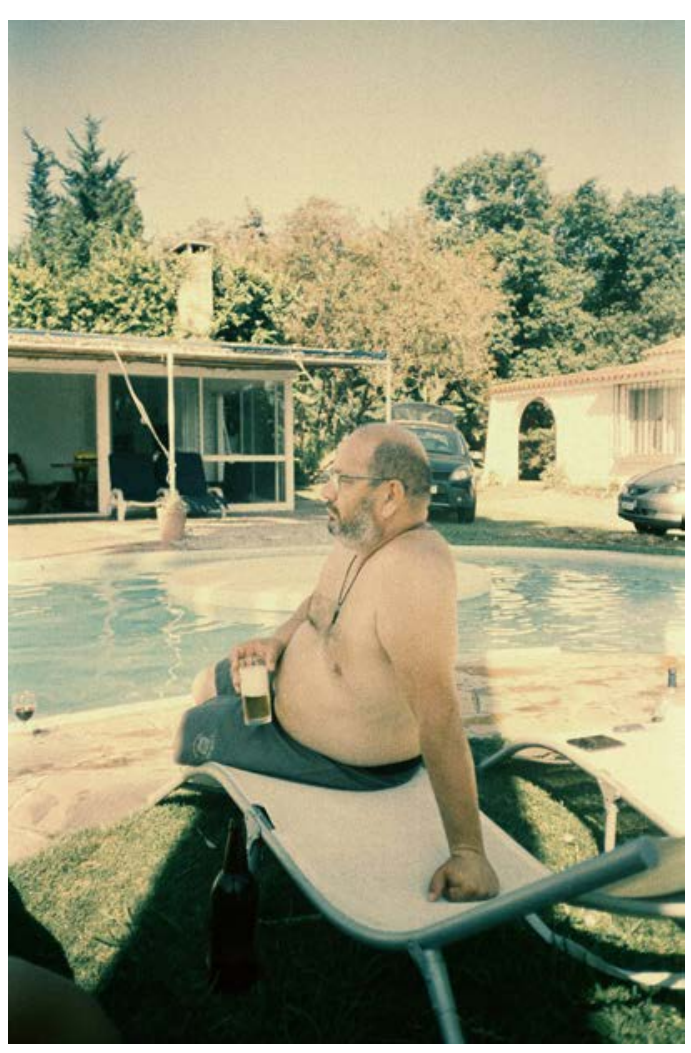

(Fig 9) Carlos bebendo a beira da piscina, Hektor Kister, 2019. 


\section{La Paloma: uma história de amor, carros em fanzine}

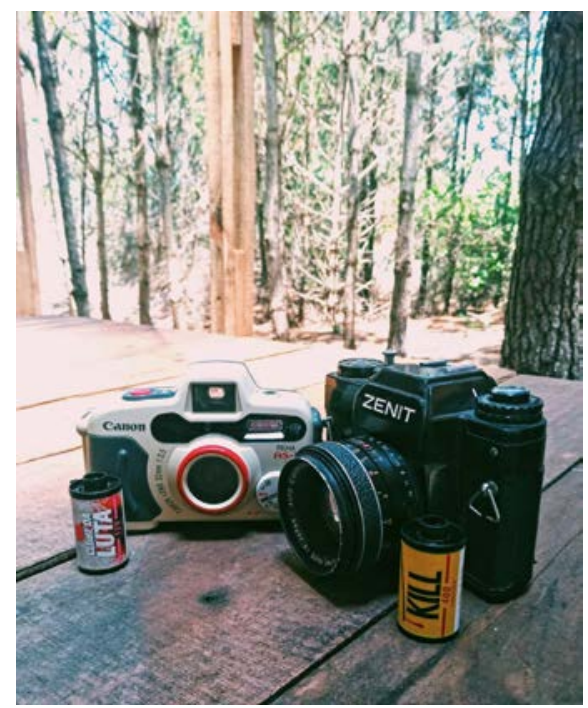

(Fig 10) Canon As1 e uma Zenit. Hektor Kister,2019.

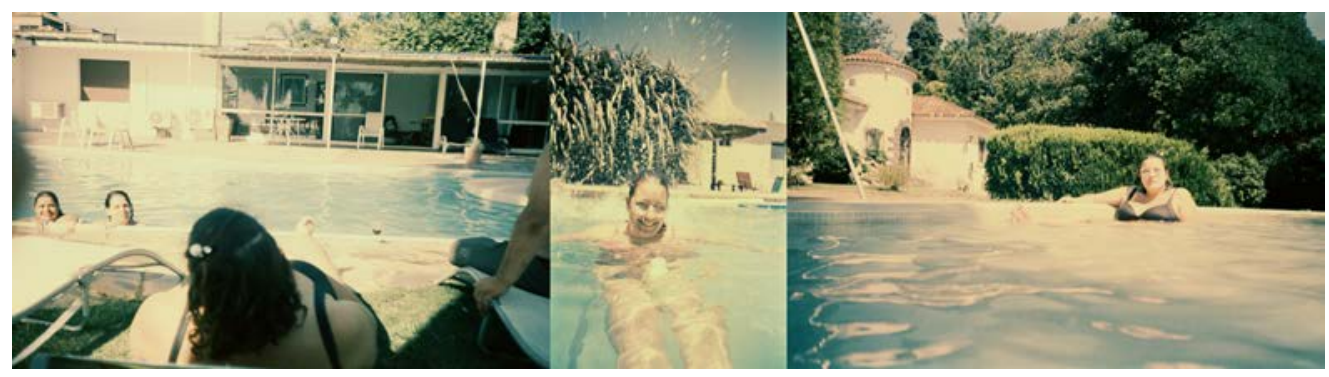

(Fig 11) Mosaico da família, Hektor Kister, 2019. 


\section{La Paloma: uma história de amor, carros em fanzine}

Esse aspecto orgânico e de maior intimidade, abre um leque de possibilidades ao produzir essas imagens, sem uma preocupação com um momento chave, mas sim com um ponto de vista e impressão direta do artista. É a partir disso que comecei a parte crucial desse trabalho, a edição e montagem desse material.

\section{E assim nasce La Paloma}

Um dos detalhes cruciais a se pensar nesse processo é a construção de uma boa narrativa, com isso comecei o processo de edição das imagens, buscando uma possível organização do material. Tate Shaw aborda um pouco desse conceito em seu artigo, da existência de uma infinidade de maneiras de amarrar uma narrativa, criando uma relação entre as imagens.

A amarração das imagens é uma ficção que o autor cria fazendo com que uma fotografia siga a outra em uma sequência. A força da ficção é que ela é irreal, mas ainda assim existe no mundo para revelar algo sobre ele. Parte da leitura de uma ficção é esquecer que você está fazendo isso. Você tem que ver inconscientemente através da tinta na página para experimentar uma consciência crescente fora do que está realmente ali. Um grande motivo para reler foto livros é a recompensa de experimentar aquela sensação mais uma vez. (Shaw,2012, p4)

Por se tratar de um material de viagem, a quantidade de fotos tende a ser grande, ainda mais porque a viagem foi registrada de várias maneiras, de câmeras analógicas a fotos de smartphone. Meu desafio foi criar uma conexão entre as minhas imagens e os registros fotográficos da família da Luana, me apropriando da estética do zine. Como já havia 


\section{La Paloma: uma história de amor, carros em fanzine}

editado uma boa parte do meu material pessoal, organizei fisicamente algumas fotos com o material de arquivo familiar (FIGURAS 12 e 13) espalhando várias fotos pela mesa, para visualizá-las como um todo e ir conectando uma a uma de modo que elas se complementassem.
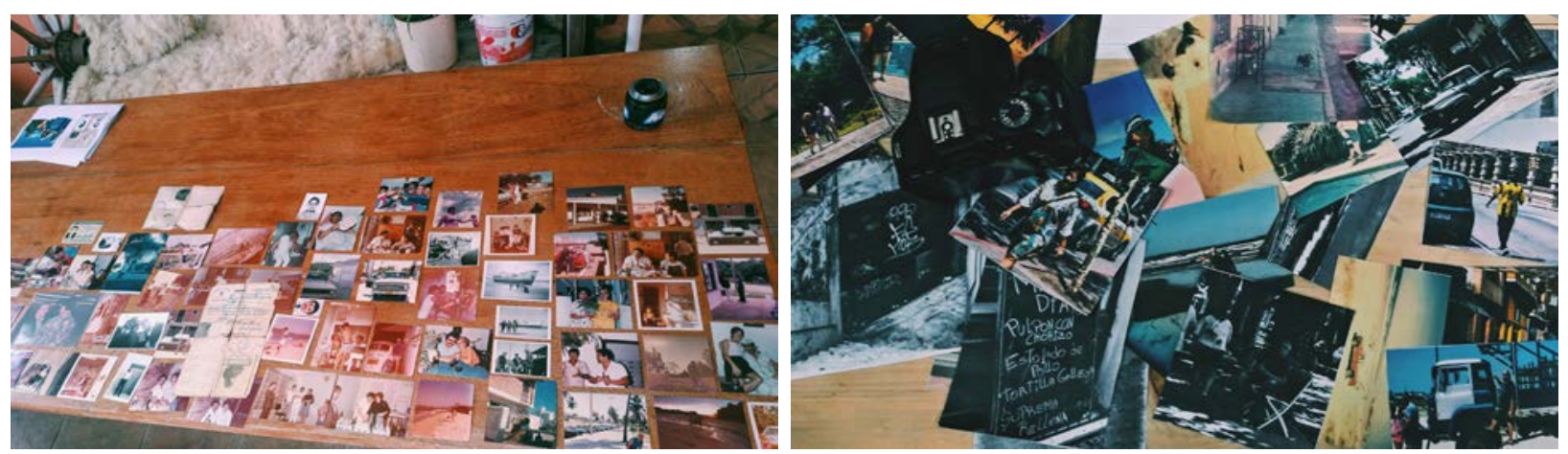

(Fig 12) Organizando o arquivo de família, Hektor Kister, 2020. (Fig 13) Bagunça organizada, Hektor Kister, 2020.

A ideia da narrativa, em conjunto com as imagens de arquivos, não é contar uma história baseada naqueles registros ou nos relatos que me foram contados, mas sim construir uma conexão de momentos através desse diálogo das imagens. Um exemplo disso, parte da minha motivação ao viajar para o Uruguai eram os carros, toda minha paixão e interesse, somados ao breve relato de adolescência do sonho de um colega, foram o que me despertou curiosidade pelo país. Em cada trecho que rodava, procurava por veículos que não encontrava por aqui, mas, em determinado momento, me deparo com uma Willys Rural (FIGURA 14), que para mim tinha grande importância 


\section{La Paloma: uma história de amor, carros em fanzine}

como registro, pois foi o primeiro veículo que tive e aprendi a dirigir. A ideia ao colocar essa foto na página era criar um ponto de conexão com a minha história. Provisoriamente coloquei uma foto dela no conjunto, em sobreposição, mas pensando em substituí-la por outro objeto que crie essa conexão indireta.

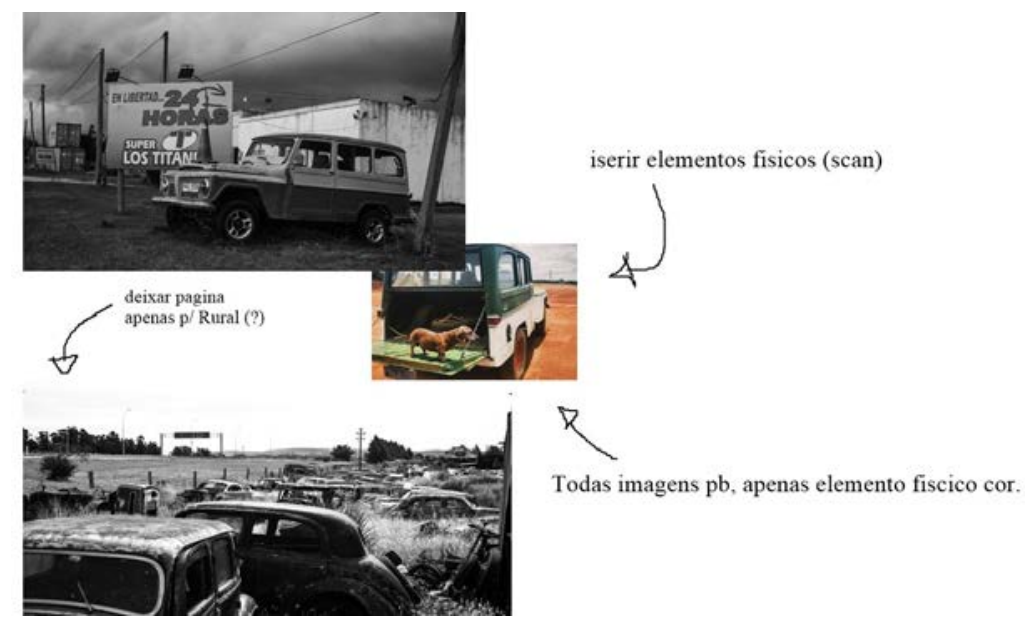

(Fig 14) Exemplo de pagina zine, Hektor Kister, 2020

Essas memórias visuais se devem muito a minha inspiração nos Road Movies $^{2}$, ao pensar em registros nas estradas uruguaias, que muito se assemelham as estradas que cortam os Estados unidos em filmes como Paris, Texas e Corrida contra o destino. Em paralelo a essa estética, muito

2 Gênero cinematográfico que se popularizou na década 70 com a ascensão da cultura Beatnik influenciados por escritores como Jack Kuroac e músicos como Bob Dylan. No geral são filmes sobre personagens que abdicam da vida cotidiana e se aventuram estrada a fora em busca de uma nova perspectiva. Corrida contra o destino, Easy Rider, Corrida sem fim e Paris, Texas são bons exemplos do gênero. 


\section{La Paloma: uma história de amor, carros em fanzine}

do material que produzi é influenciado por fotógrafos como Jamel Schabazz, Boogie, Martin Parr e Glen E. Friedman. Esses nomes foram de grande importância ao pensar um contexto mais urbano (FIGURA 15) Por exemplo, a imagem desse garoto em uma pista de skate em La Paloma, hoje vejo muito o peso do trabalho de Friedman nos registros do cenário do skate californiano, combinado as cores fortes dos registros de praia de Martin Parr (FIGURA 16). Ilustro esse comparativo com um mosaico das duas imagens, na primeira, Friedman registra Jay Adams andando em uma piscina na California. Na imagem seguinte, a saturação das praias da Espanha por Martin Parr.

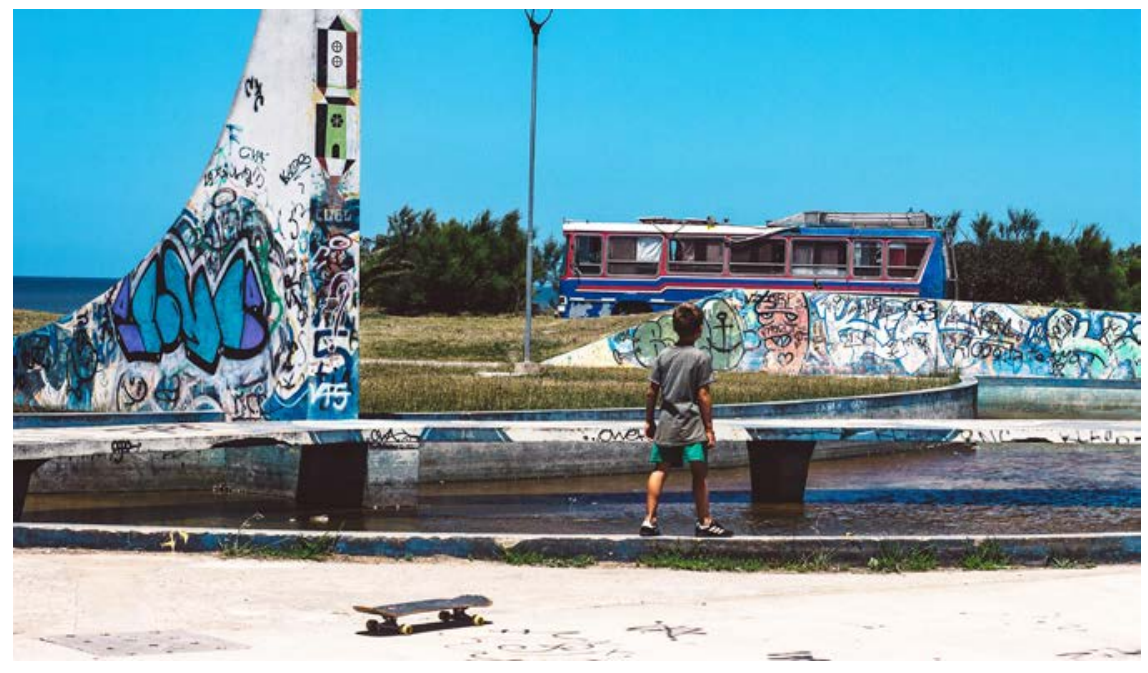

(Fig15). La paloma, Hektor Kister, 2020.

Fonte: o próprio autor 


\section{La Paloma: uma história de amor, carros em fanzine}

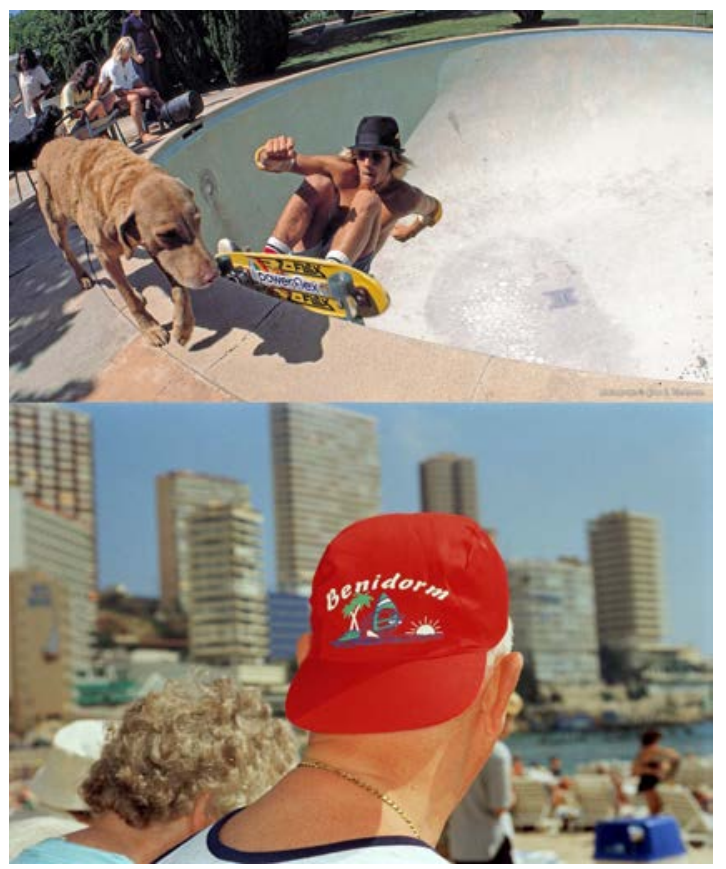

(Fig.16) Jay Adams dog bowl, Glen E. Friedman, 1977 \& Benidorm, Espanha, Martin Parr, 1999. Fonte: Glen E. Friedman // Magnum Photos de páginas, o processo de visualização do objeto físico faz toda a diferença.

Com todo o material organizado, próximo passo é construir um esboço, ou também conhecido como boneco. Nessa primeira versão eu fiz tudo manualmente, colando foto a foto por página, com o intuito de ver possíveis formatos de imagem, cortes, diagramações e onde faria as sobreposições com os materiais de arquivo. Essa parte é importante para facilitar a construção do produto final, visualizando-o fisicamente. Isso melhora a noção da quantidade de páginas, a posição de cada imagem e se determinada diagramação funciona ou não.

Nessa primeira versão, meu material ao todo ficou com aproximadamente 60 páginas, o que para uma revista ou foto livro é aceitável, mas por se tratar de um zine, foge muito da ideia de algo de baixo custo, então o mais cabível seria algo entre 35 a 45 páginas. Como as imagens foram todas coladas manualmente (FIGURA 17) utilizei sulfite comum e imprimi muitas das fotos em casa. Mesmo com a grande quantidade

Revista Tuiuti: Ciência e Cultura, v.7 n.62. p. 18-45, Curitiba, 2021 


\section{La Paloma: uma história de amor, carros em fanzine}

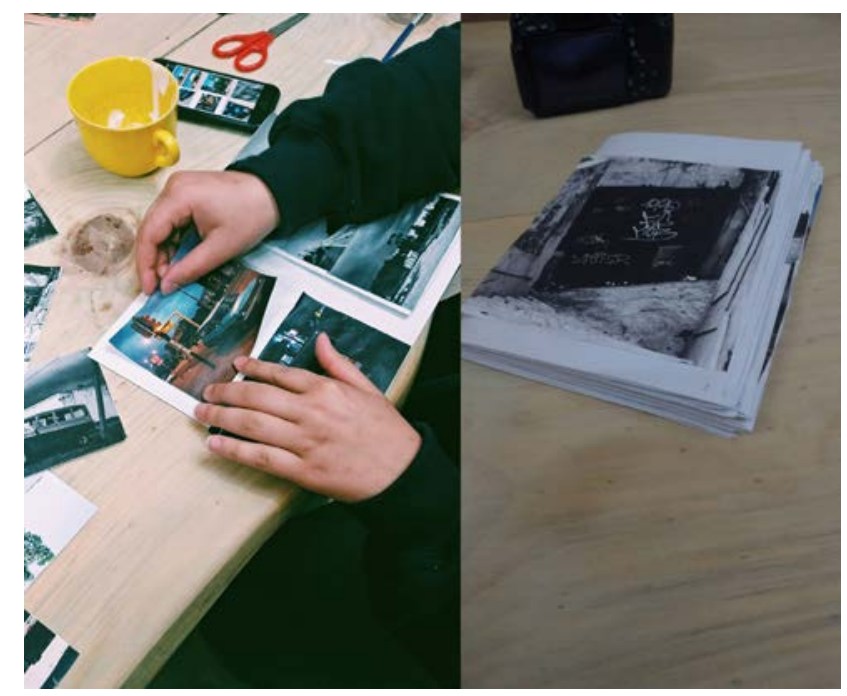

(Fig.17) Luana ajudando nas colagens e o resultado final.

Depois desse processo manual e com a quantidade decidida de páginas, vem o processo final de montagem e diagramação. Existem alguns softwares que auxiliam nessa montagem, como Lightroom, Photoshop e Canva. Por estar mais familiarizado com a praticidade do Canva, optei por construir o projeto por lá. Com a ajuda da Luana, montamos página por página do projeto fixo, apenas alterando a página central que teria uma imagem diferente em cada um dos 4 zines, com o intuito de criar um vínculo de proximidade de um conteúdo para se aproximar mais do gosto de cada um dos quatro presenteados ${ }^{3}$. O elemento crucial de um fanzine é o seu papel de impressão, não só 3 A ideia é que ao defender meu artigo no dia da banca, todos os professores tenham em mãos essa primeira tiragem do zine, se tudo ocorrer bem é 0 que irá acontecer. 


\section{La Paloma: uma história de amor, carros em fanzine}

pelo fácil acesso, mas pela personalidade que ele pode transmitir. Minha inspiração eram os álbuns antigos de família (FIGURA 18), com páginas amareladas pelo tempo, porém, como isso não é tão simples de se reproduzir em tão pouco tempo, fui testando alguns papeis até chegar no que mais se assemelhava a esse aspecto de algo antigo, até que cheguei no papel Canson Fine face creme e, ao ver as imagens impressas (FIGURA 19), e as cores fortes combinando com o tom amarelado do papel, encontrei o último detalhe que precisava para concluir esse projeto. Apesar de não estar pronto com o material apropriado, imprimi algumas versões para ter uma noção de como será o produto final, já com a capa (FIGURA 20) com vários documentos, fotos e outros objetos, todos sobrepostos como uma grande colagem, era a forma ideal de se fazer uma capa digna de um fanzine, na imagem ao lado ainda com papel comum, os testes finais já montado na estrutura, ainda com espaços para marcações. Além das sobreposições na capa, existe interferências (FIGURA 21) nas imagens, na seguinte pagina combinei algumas fotos do Seu Gabino em uma adega de vinhos em conjunto a uma foto minha em um bar em Punta Del Este.

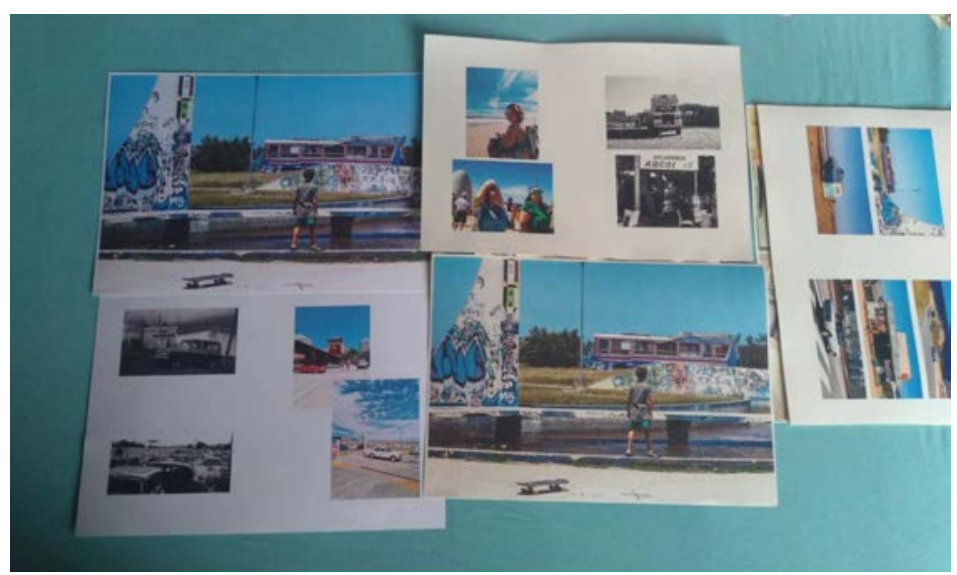

(Fig.18) álbum "secreto" do Senhor Gabino Fonte: o próprio autor. 


\section{La Paloma: uma história de amor, carros em fanzine}

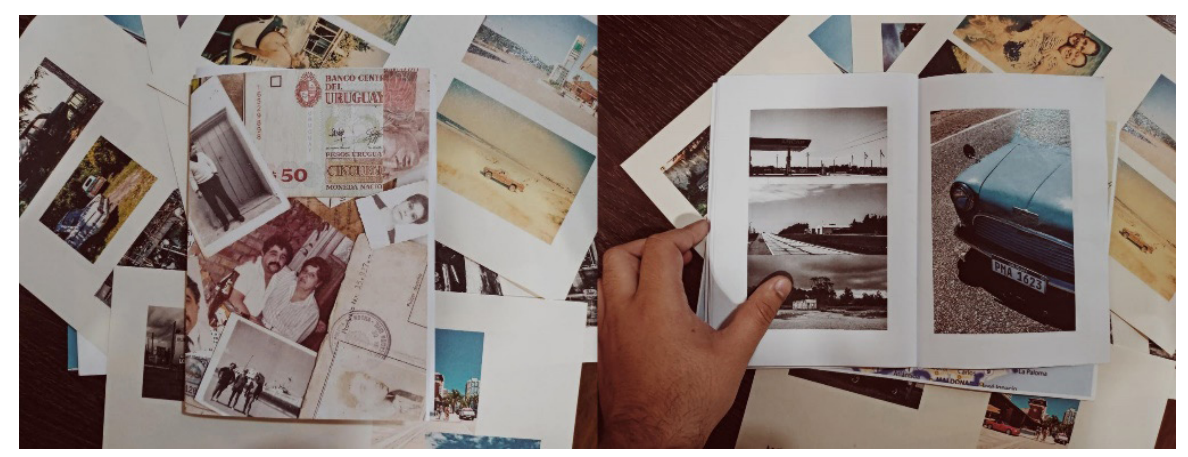

(Fig.19) Testes e mais testes para chegar no produto final Fonte: o próprio autor.

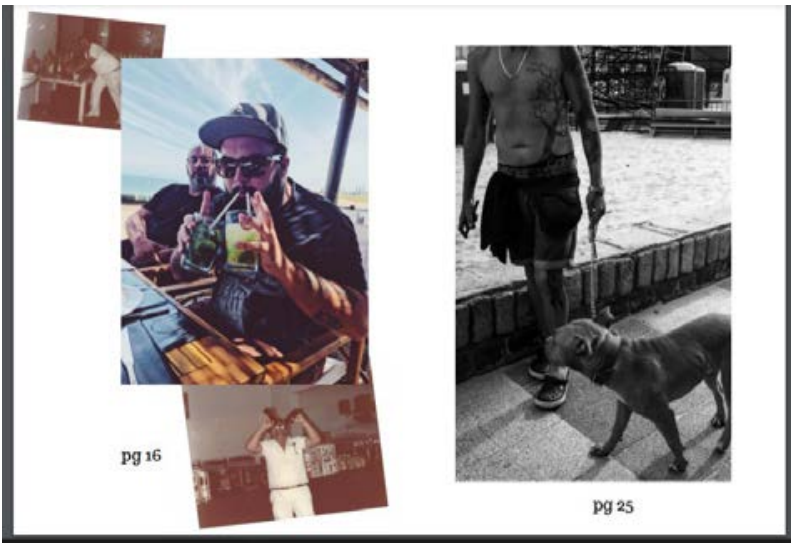

(Fig.20) Capa e um esboço do projeto final Fonte: o próprio autor. 


\section{La Paloma: uma história de amor, carros em fanzine}

Esse detalhe foi crucial para passar a personalidade que tanto busquei ao idealizar esse projeto, por mais que seu objetivo seja o de um fanz̨ine fotográfico, seu espirito é de um álbum de família, registros de viagem, algo íntimo e que, por meio dessas escolhas, vão transportar cada um que o folhear para um Uruguai muito diferente daquele dos panfletos de hotéis e guias turísticos, o Uruguai pelo meu ponto de vista.

\section{Conclusão}

Assim como iniciei o meu relato de viagem, depois de longas páginas escritas, vista embaralhada e uma certa confusão mental, concluo esse projeto. Mais do que esse 1 ano em que passei estudando essa história, são mais 2 anos em que pensei em prestar uma homenagem digna a toda essa família que me inspirou, me acolheu e me possibilitou a pôr em prática essa ideia. Nessa altura, o que posso concluir que é muito mais difícil e complexo falar sobre aquilo que gosto. Nesses meses de pesquisa me deparei com becos sem saída, partindo do ponto de que o fanzine é um assunto muito pouco explorado, e quem está lendo pode pensar que esse seria o maior problema e que logo acabariam os materiais de pesquisa. Mas foi o contrário, a parte mais difícil é narrar uma história que não vivi! Tanto ao estruturar o fanzine quanto no relato no artigo, em inúmeros momentos me questionei se estava indo por um caminho certo, afinal muitos desses momentos não tinham a emoção ou magia de um conto de fadas, era a realidade.

Ao invés de narrar todos os fatos com fidelidade, preferi contar isso através das memórias, pequenas histórias amarradas umas às outras, já que foi assim que conheci muitas delas. Por meio dessas memórias, transporto tanto os que estão lendo o relato quanto os que estão folheando o 


\section{La Paloma: uma história de amor, carros em fanzine}

fanzine para uma longa jornada em uma estrada vazia no qual para me manter acordado, viajei por um romance proibido e um sonho juvenil.

Além da importância de trabalhar com um tema tão pouco difundido, mas, que segue sendo de grande importância para os meios alternativos, me aprofundar na história e prática fanzinesca me expandiu os campos de visão tanto para o meio acadêmico quanto por estar publicando minhas obras fisicamente. Por maior que seja a dificuldade de se falar sobre temas que lhe interessam, foi muito prazeroso se aprofundar de uma maneira analítica sobre esses temas. Por mais que eu não siga estudando sobre o tema em si, espero que esse artigo e muitos outros relacionados a esse tema seja de inspiração para projetos como esse.

\section{Referências}

LOURENÇO. Denise. Fanzine: Procedimentos construtivos em mídia tática impressa 2006.

Disponível em: https://sapientia.pucsp.br/bitstream/handle/4889/1/Denise.pdf_

RITCHIN, Fred. Bending the Frame: Photojournalism, Documentary and the Citizen. New

York: W. W. Norton 2013. Disponível em:

https://www.academia.edu/6323837/Book_Review_Fred_Ritchin_Bending_the_Frame_

Photojournalism_Documentary_and_the_Citizen

FRIEDMAN. Glen. Glen E. Friedman's Tribute Jay Adams 1977. Disponível em: http://www. xgames.com/xgames/gallery/11359393/image/3/dog-bowl-1977

SCHNEIDER. Grace. Jornalismo e tecnologias digitais 2015. Disponível em: https://wwwacademia. edu/37256256/Jornalismo_e_Tecnologias_Digitais_produção_qualidade_e_participação 


\section{La Paloma: uma história de amor, carros em fanzine}

JOKELA. Markus. Table Rock 1992, 2016. Disponível em: https://www.worldpressphoto.org/ collection/photo/2017/28784/24/2017-Markus-Jokela-LTP3-TAD

PHOTOS. Magnum. Martin Parr's Benidorm 1999. Disponível em:

https://www.magnumphotos.com/arts-culture/society-arts-culture/martin-parr-benidorm/

MALTZ. Rony. Zines e fotografia: Uma história de resistência em tempos digitais. Revista Zum 2018. Disponível em: https://revistazum.com.br/radar/zines-fotografia/

MCCURRY. STEVE. Afghanistan 1984. Disponível em: https://davidcharlesfox.com/stevemccurry-revealing-the-worlds-true-colours/

SHAW. Tate. The Photobook Review 2012. Disponível em:

https://www.carloshenriquesiqueira.com/post/ligação-estratégica-amarração-e-sequência-emfotolivros

UOL. O pasquim faz 50 anos e ganha exposição em São Paulo 2019. Disponível em:

https://entretenimento.uol.com.br/noticias/redacao/2019/11/05/o-pasquim-faz-50-anos-eganha-exposicao-em-sao-paulo.htm

VICE. Pouca gente curte punk rock no interior racista da África do Sul 2013. Disponível em: https://www.vice.com/pt/article/ypmwam/pouca-gente-curte-punk-rock-no-interior-racistada-africa-do-sul.

Submetido em 10 de março de 2021

Aceito em 15 de maio de 2021

Publicado em 8 de julho de 2021 